\title{
THERMAL PROPERTIES OF FROZEN FOOD: A REVIEW ARTICLE
}

\author{
Pooja Sri V S \\ Scholar, Food processing and preservation technology, Dept., of School of Engineering, \\ Avinashilingam Institute for Home Science and Higher Education for Women, Coimbatore, TamilNadu, India
}

\begin{abstract}
Food is a mixture of solutes and water particles. The properties of the food material vary by the state of water particles present in them. The density, viscosity are some of the factors that attribute to the difference in thermal properties between frozen and unfrozen food. Several studies have been made in analyzing the thermal properties of frozen food of different varieties from frozen soup pouches to frozen meat. Several properties related to thermic properties such as thermal conductivity, latent heat, heat capacity is also under consideration. For instance, density is found using the known volume of the sample, porosity using water, and so on. Thus thermal properties of frozen food are of immense importance for developmental processes.
\end{abstract}

Keywords - Water, Thermal property, Frozen food, Preservation.

\section{INTRODUCTION}

Food contains some water particles so that they can be frozen and preserved. For the food to be frozen and preserved, their thermal properties are of greater importance to get a clear idea on freezing properties, the shelf life of the product, and so on. The properties are immensely studied and noted precisely for designing process equipment and processing method development. Food is a mixture of solutes and water particles. Thus their freezing properties vary according to the food. Water is one of the major components which plays a vital role in the freezing operation. Water makes the food freeze and aids in preservation. [1]

Normally Water is an essential component of food. They are present both as inter and extracellular water. The properties, the behavior, the texture of the food mainly depends upon the amount of water present in them. The chemical and biological changes in food occur mainly because of the water present in them. Water has standard physical and chemical properties which will be altered upon changing their physical state i.e., of different forms like water vapor or liquid water or an ice cube. [2]

Frozen food is one of the most widely used food products around the globe. These foods can be used worldwide during all the seasons. The nutrients and availability of seasonal food for the people around the year is the primary purpose of processing and production of frozen food. Usually freezing of the seasonal food is more preferred rather than that of thermal preservation as thermal preservation leads to deterioration of its sensory and quality upon overheating. Thus appropriate freezing of the food can just inactivate the food's quality so that it can be made fresh on proper heating. For understanding freezing and its effects on food, it is essential to know about its thermodynamic and kinetic properties. Now we will see about the thermal properties of frozen food. [3]

The rest of the paper is organized as follows. Discussion in section II. Conclusion in section III Acknowledgement given in section IV and Reference in Section V.

\section{DISCUSSION}

Many properties of food and water such as freezing point, density, thermal conductivity will be studied for understanding the thermal properties of frozen food.

\section{A. Freezing Point-}

The Freezing point is the temperature at which the liquid freezes and hence changes its state from liquid to solid. Normally the freezing point of water is $0^{\circ} \mathrm{C}$. But on considering the water present in food materials, the water is present as solute along with other food particles. Thus it can be concluded that a freezing point depression can be observed when the water is present in food along with other particles. Clear knowledge of the composition of food is necessary for determining the freezing point and evaluating the freezing point depreciation. [4,5] For calculating the freezing point of the food, according to Schwartzberg,

$$
T_{k}=-0.141-4.36 \frac{x_{n}}{x_{w}}-43.5 \frac{x_{m}}{x_{v e}}
$$

Where $\mathrm{x}_{\mathrm{w}}$ means water mass fraction,

$\mathrm{x}_{\mathrm{a}}$ - ash mass fraction,

$\mathrm{x}_{\mathrm{o}}-$ other components mass fraction. [6]

On using this formula, the freezing point can be found and the freezing point depreciation can be found.

\section{B. Specific Heat Capacity and Latent Heat -}

It is the heat required to raise the temperature of 1 gram of a substance to 1 degree. Water has quite a larger amount of Specific Heat Capacity (cp) i.e., $4.18 \mathrm{~J} / \mathrm{g}{ }^{\circ} \mathrm{C}$ at $20^{\circ} \mathrm{C}$ whereas cp of $2 \mathrm{~J} / \mathrm{g}{ }^{\circ} \mathrm{C}$. In the same way, Latent heat is the energy 


\section{International Journal of Engineering Applied Sciences and Technology, 2020 \\ Vol. 5, Issue 5, ISSN No. 2455-2143, Pages 162-165 \\ Published Online September 2020 in IJEAST (http://www.ijeast.com)}

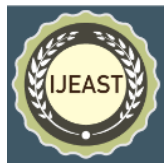

released or absorbed during a phase change of the sample. On considering water, the latent heat of water (melting of ice or crystallization of water) is $334 \mathrm{~J} / \mathrm{g}$ at $1 \mathrm{bar}, 0{ }^{\circ} \mathrm{C}$, which is considerably large. [7, 8]

Specific heat capacity and the Latent heat being high, the energy required for freezing food increases with an increase in the amount of water present in food. For finding the cp of the frozen food, first, the food is considered as a binary solution at sub-freezing temperatures and constant pressure. [1]

\section{Density -}

The density of water is found to be $1 \mathrm{~g} / \mathrm{cm} 3$ whereas the density of ice is found to be $0.93 \mathrm{~g} / \mathrm{cm} 3$. It is notable that density decrease with an increase in volume. In the freezing process, the water present in the food tends to freeze thus expanding and decreasing the density of the food material. An important factor to be noted is that the freezing first occurs at the surface and in centre at the final. The fact that freezing leads to expansion plays a major role here. First, on surface freezing, the expansion does not have any major impact. But freezing at the centre portion after the surface freezing requires some extra space for expansion leading to the formation of thermal stress and cracks which has a drawback in the quality of the food.

One of the best methods for the determination of the density of the food sample is using Pycnometer. [9, 10]

\section{Enthalpy -}

Enthalpy of food is the combination of all the energy present in food. Enthalpy is mainly considered for developing a model for the food product. The internal energy differs for frozen and unfrozen food. Thus on finding the enthalpy $\mathrm{H}$, the food can be precisely designed and frozen and preserved. The enthalpy of the sample can be found using the formula (2)

$$
\mathrm{H}(\mathrm{T})=\int_{\text {Tref }}^{T} \mathrm{cp}\left(T^{l}\right) d T^{\prime}
$$

Where $\mathrm{H}$ is the Enthalpy, $\mathrm{T}$ is the ambient temperature, $\mathrm{T}_{\text {ref }}$ is the reference temperature and $c_{p}$ is the specific heat of the food. [11-13]

\section{E. Thermal Conductivity -}

Thermal conductivity is the amount of heat that can be transferred through the thickness in a direction normal to the surface. In the case of food, the thermal conductivity rate mostly depends on the water present. Generally, notably, that the thermal conductivity of water is greater than the other food matrix such as Protein, fat, etc. For determining the thermal conductivity of frozen food, some assumptions are to be made on structure. [11,14] But for the precise calculation of the thermal conductivity, Choi's and Oko's method for the prediction of the thermal conductivity is used by considering the moisture content of the frozen food sample rather than considering the structure of the food. The formula used goes as follows, [15]

$$
\mathrm{K}=0.58 \mathrm{X}_{\mathrm{w}}+0.155 \mathrm{X}_{\mathrm{p}}+0.25 \mathrm{X}_{\mathrm{c}}+0.16 \mathrm{X}_{\mathrm{f}}+0.135 \mathrm{X}_{\mathrm{a}}
$$
$\mathrm{W} / \mathrm{m}^{\circ} \mathrm{K}$

Where $X_{w}$ is the Water fraction

$\mathrm{X}_{\mathrm{p}}$ is the Protein fraction

$\mathrm{X}_{\mathrm{c}}$ is the Carbohydrate fraction

$\mathrm{X}_{\mathrm{f}}$ is the Fat fraction and

$\mathrm{X}_{\mathrm{a}}$ is the Ash fraction.

The Thermal conductivity of food is found to determine its shelf life in various atmospheric conditions. If the thermal conductivity of the food is less, the heat transfer to the frozen food will be less so that it can be kept at normal room temperature and thus its thawing takes a longer time, whereas the food with higher thermal conductivity will be thawed very quickly at normal room temperature and its preservation will be at a risk. So frozen food with a lower thermal conductivity rate will me much preserved. $[16,17]$

\section{F. Thermal Diffusivity -}

It is the rate at which the heat can be transferred from one end to the other end per volume of the sample. This also plays a role in designing the food product for preservation. It comes in relation to thermal conductivity, density, and specific heat of the food product. The calculation of the thermal diffusivity is very easy and simple as compared to that of all the other thermal properties. It is as follows,

$$
\alpha=\frac{k}{\rho c}
$$

Where $\alpha$ is thermal diffusivity,

$\mathrm{k}$ is thermal conductivity,

$\rho$ is density, and

$\mathrm{c}$ is specific heat. [18-20]

As same as thermal conductivity, the thermal diffusivity plays its role in the designing and modelling of food products. 


\section{International Journal of Engineering Applied Sciences and Technology, 2020 \\ Vol. 5, Issue 5, ISSN No. 2455-2143, Pages 162-165 \\ Published Online September 2020 in IJEAST (http://www.ijeast.com)}

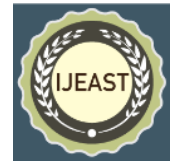

\section{G. Surface Heat Transfer Coefficient -}

The Surface Heat Transfer Coefficient $(h)$ is determined for predicting the time taken for freezing of the food product during the freezing processes. Since the freezing is done by an external body, the surface heat transfer coefficient ensures the time taken by the food to freeze considering the shape, surface of the product, etc. The packaging material also comes into consideration for determining $h$, since even if the food takes lesser time to freeze, the packaging material will have its $h$ value and it may take some more time to freeze. Thus food products should be frozen separately and vacuum packed in a material of high $h$ value so that it will be heat stable and will have a longer shelf life. $[1,21]$

\section{CONCLUSION}

Determination of the several thermal properties of food helps in designing and modelling of food products and development of techniques for the production and preservation of food by the freezing method. Freezing is one of the best methods to preserve the food for a longer time and determination of the thermal properties of frozen food aids in finding its shelf life and its nature to resistance to normal ambient temperatures. It is proven to be that frozen and preserved food tends to retain the nutrient quality and the natural texture of the food than that of the heat preserved food. So it would be recommended that the food can be more preserved by freezing method rather than that of the heating method for retaining the sensory and physical quality of the processed food. And that the thermal properties of frozen food help in determining the time for the preservation of the sensory and physical quality of the same. Frozen food will be available for a long time and thawing helps in bringing the food to normal condition. Thus Thermal Properties of Frozen food are found to evaluate its time period, quality and preservation capacity. [1, 2, 22, 23]

\section{ACKNOWLEDGEMENT}

I would like to thank all my staffs and my department Head for encouraging my work and for their continuous support and motivation for completing this review article. My sincere thanks to my senior who guided me in all the ways possible to make this work done without and mistakes.

\section{REFERENCE}

[1]. Nesvadba, Paul. "Thermal properties and ice crystal development in frozen foods." Frozen food science and technology (2008): 1.

[2]. deMan J.M. (1999) Water. In: Principles of Food Chemistry. Food Science Text Series. Springer, Boston, MA.

[3]. Singh, R. P. (1995). Thermal properties of frozen foods. Engineering properties of foods, 49-88.
[4]. Góral, D., \& Kluza, F. (2002). Experimental and analytical determination of freezing point depression. Electr J Polish Agric Univ, Agric Engr, 5(2).

[5]. Pham Q. T., 1996. Prediction of calorimetric properties and freezing time of foods from composition data. J. Food Eng. 30, 95-107.

[6]. SCHWARTZBERG, H. G. (1976). Effective heat capacities for the freezing and thawing of food. Journal of Food Science, 41(1), 152-156.

[7]. Pham, Q. T. (2006). Modelling heat and mass transfer in frozen foods: a review. International Journal of Refrigeration, 29(6), 876-888.

[8]. Verboven, P., Scheerlinck, N. and Nicola"1, B.M. (2003). Surface heat transfer coefficients to stationary spherical particles in an experimental unit for hydrofluidisation freezing of individual foods.International Journal of Refrigeration 26(3), 328-336.

[9]. Rahman, M. S., \& Driscoll, R. H. (1994). Density of fresh and frozen seafood. Journal of food process engineering, 17(2), 121-140.

[10]. Mallett, C. P. (Ed.). (1993). Frozen food technology. Springer Science \& Business Media.

[11]. Van der Sman, R. G. M. (2008). Prediction of enthalpy and thermal conductivity of frozen meat and fish products from composition data. Journal of Food Engineering, 84(3), 400-412.

[12]. van Sleeuwen, R. M., \& Heldman, D. (2003). Frozen food enthalpy. Encyclopedia of Agricultural, Food, and Biological Engineering, Marcel Dekker Inc., New York, United States, 402-409.

[13]. KERR, W. L., JU, J., \& REID, D. S. (1993). Enthalpy of frozen foods determined by differential compensated calorimetry. Journal of food science, 58(3), 675-679.

[14]. Carson, J. K. (2006). Review of effective thermal conductivity models for foods. International Journal of Refrigeration, 29(6), 958-967.

[15]. Choi, Y. and Okos, M.R. (1986). Effects of temperature and composition on the thermal properties of foods. In: M. Le Maguer and P. Jelen, eds. Food Engineering and Process Applications, Vol. 1, Transport Phenomena. New York: Elsevier, pp. 93-101.

[16]. Miyawaki, O., \& Pongsawatmanit, R. (1994). Mathematical analysis of the effective thermal conductivity of food materials in the frozen state. Bioscience, biotechnology, and biochemistry, 58(7), 1222-1225.

[17]. Oikonomopoulou, V. P., Krokida, M. K., \& Karathanos, V. T. (2011). The influence of freeze drying conditions on microstructural changes of food products. Procedia food science, 1, 647-654. 
[18]. Miyawaki, O. (2001). Analysis and control of ice crystal structure in frozen food and their application to food processing. Food Science and Technology Research, 7(1), 1-7.(TD)

[19]. Moureh, Jean, and Evelyne Derens. "Numerical modelling of the temperature increase in frozen food packaged in pallets in the distribution chain." International Journal of Refrigeration 23, no. 7 (2000): 540-552.(TD)

[20]. Murakami, E. G., \& Okos, M. R. (1989). Measurement and prediction of thermal properties of foods. In Food properties and computer-aided engineering of food processing systems (pp. 3-48). Springer, Dordrecht.(TD)

[21]. Anderson, B.A. and Singh, R.P. (2006). Effective heat transfer coefficient measurement during air impingement thawing using an inverse method. International Journal of Refrigeration 29(2), 281293.(HTC)

[22]. Rahman, M. S. (Ed.). (2009). Food properties handbook. CRC press.(con)

[23]. Sun, D. W. (Ed.). (2016). Handbook of frozen food processing and packaging. CRC press.(con) 